\title{
Content analysis of levels and aspects of comprehension in West African senior secondary school examination
}

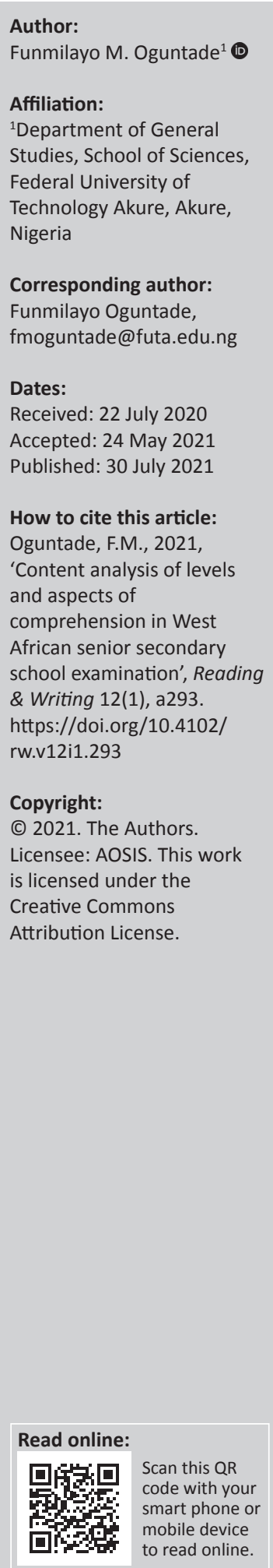

Background: Reading is one of the most complex and exclusively human mental activities. It is a foundational skill for all learning, whether at primary, secondary or tertiary levels. If students do not master effective strategies for reading, they may not be successful independent learners. The ability to comprehend written texts and answer relevant questions on them is a major feature that is examined in comprehension in the West African Senior Secondary School Certificate Examination.

Objective: This study was directed at analysing the content of the English language comprehension questions in the West African School Certificate Examination to identify the intensities of testing different aspects of comprehension so that teachers can lay emphasis on these aspects when they teach reading strategies to their students.

Method: The content analytical approach was used to identify the different aspects and levels of the comprehension passages. The analysis of the content was carried out by focusing on 10 different content sub-categories.

Results: The study revealed that most of the comprehension passages presented had never been used before and they were related to the students' local environment. Literal and inferential questions dominated while critical and evaluative questions were rarely asked.

Conclusion: In the light of the pedagogic importance of critical and evaluative questions, it is recommended that examiners and teachers should lay emphasis on questions that demand higher-order reasoning to prepare students for the contemporary demands of literacy. In line with higher-order questions, it is also suggested that the curriculum should be amended to encourage critical evaluative thinking among secondary school students as it is an important part of literacy and language development.

Keywords: content analysis; language testing; comprehension passages; secondary school.

\section{Introduction}

Reading is one of the most complex and exclusively human mental activities. It is one of the language skills that people must acquire before they can be considered literate. Reading is an important aspect of learning a language or learning in general. Reading is a receptive skill just like listening (Oyinloye 2002). Reading involves eye movement, speech, comprehension and vocabulary. In Nigeria, where this study is situated, students have varying levels of text comprehension. This could be attributed to the students' levels of independent reading, their socio-economic background, or their cognitive ability to interact with the coded message in a text, among many other factors (Oyetunde 2002). Jude and Ajayi (2012) posit that the problem of poor reading comprehension usually leads to low academic achievement levels, which may lead to failure, frustration in reading and even students dropping out of schools. Comprehension involves reasoning and the ability to make meaningful interpretation of written symbols throughout the reading process. In reading comprehension, the readers require the vital skill to read and recognise the form and supporting ideas of an argument, grasp details, and recast using their background knowledge, to understand complex ideas presented in a given text. Comprehension is the aptitude to respond appropriately to matters raised in the text in question form. Comprehension is defined as the ability to respond correctly to questions derived through 'wh'-question transformations on the syntactic structure of given passages (Jude \& Ajayi 2012). Cabral and Tavares (2002) assert that when one reads, it is imperative to understand what has been read; students who cannot readily reconstruct the author's main idea, or identify the 
supporting ideas and supporting facts as well as some critical evaluation of a given passage or text, cannot read for their course, irrespective of what types of material they read outside of class. Reading comprehension is the ability to read, understand, process, and recall what was just read. Rutzler (2020) submits that having excellent reading comprehension skills is crucial because it increases the enjoyment and effectiveness of reading and helps people academically, professionally and in real life. Students in secondary schools are being trained for the challenges of higher learning in higher institutions. A student that is not properly established in literacy skills may find it difficult to cope at the tertiary level. The development of essential intellectual and study skills, namely reading, writing and reasoning, is stated to be the basis for the success of any tertiary student (Fairbairn \& Winch 1996). The ability to read with understanding should, however, not be taken for granted. Not all students can read proficiently at the required level for successful academic performance.

Teachers of English language in secondary schools in Nigeria, Ghana, Sierra Leone, The Gambia and Liberia are expected to cover the entire curriculum for English language as designed by the West African Examination Council (WAEC). The curriculum is designed to help learners understand spoken English, to be understood when communicating in English, to be able to comprehend what they read, and to write effectively for others to understand. The different competencies of teachers of the English language, and their interest in different aspects of the subject matter, may result in teachers laying more emphasis on certain aspects of the English Language curriculum than others. English is the medium of communication in the five countries that jointly run the WAEC. English is thus a critical subject that students must pass at credit level to proceed to a higher institution in all the countries where the examination is conducted. The ability of students to comprehend written text and answer questions on them is a major feature that is examined in the comprehension section of the West African Senior Secondary School Certificate Examination (WASSCE). This study was directed at examining the content of the English Language comprehension questions in the WASSCE to identify the intensities of testing of different aspects of the comprehension examination paper. This is an area that is yet to be covered by researchers. The main aim of this study is embedded in the research questions: what are the various contents of comprehension passages in WASSCE? What are the levels and the aspects of comprehension tested in the WASSCE English Language examination?

\section{Importance of reading comprehension}

Comprehension skills are important in language fluency and are necessary for language and literacy development. They are related to all subjects and are imperative to advancement in school. Strong comprehension skills are required for students to excel in standardised state testing as well as placement testing at primary, secondary and tertiary levels. Comprehension skills need to be applied by students at all levels of education. It is a skill that every student must practise frequently throughout every level of school. Reading comprehension skills will help students not only in English class but in all areas of academic study. Moore (2016) posits that comprehension skills acquired early in life and practised often and refined throughout primary school and secondary school will ensure students' success in tertiary institutions and in their future career (Moore 2016). Reading is one of the most important academic tasks carried out by students either in primary or secondary schools, or tertiary institutions. The only difference is that students are exposed to several texts and textbooks that require independent reading in the tertiary institutions and at this level they are expected to comprehend what they read so that they can analyse, critique, evaluate and synthesise information from various sources. Unfortunately, many students gaining admission into these tertiary institutions are ill-prepared to meet these challenges. Many researchers in applied linguistics and reading research have shown that there is a relationship between reading proficiency and academic success (Grisso 2018; Stoffelsma \& Spooren 2018). They believe that poor reading ability results in poor academic attainment which eventually affects overall literacy development. At secondary schools in Nigeria, students are required to read and understand texts from many different content areas in schools. Thus students at this level need to develop the necessary reading skills to succeed in their academics. Many of them do not have problems with reading words accurately but lack comprehension. Given the impact that reading comprehension has on secondary school students' success in their academics, it is essential to look at the contents of the comprehension examination in WASSCE. This will reveal the aspects and levels of comprehension in which the students need to have proficiency.

\section{Aspects and levels of comprehension}

The Centre for Canadian Language Benchmarks (2015) asserts that understanding listening or reading texts generally entails three main levels of comprehension, namely literal, interpretive and applied. On the other hand, Campton College (n.d.) identifies six levels of comprehension: literal, inferential, appreciative, critique, evaluative and essential. Other researchers, such as Ofodu, Babalola and Dada (2010) and Lasisi (2003), identify literal, inferential, and critical or evaluative levels of comprehension. For many years, until recently, WAEC ensured that two comprehension passages were given to their students. This is an indication that they are interested in the impact comprehension can have on students. The content of the comprehension passages and the level of comprehension tested were looked into critically to see the trend of questions, types of comprehension and sources (excerpt or newly composed) of the comprehension passages given to students in WASSCE over the years so that researchers can make recommendations on what can be done to help students and determine ways to improve any shortcomings or gaps that may be discovered. 
This study uses three levels of comprehension, namely literal, inferential or interpretive, and critical or evaluative. The literal level of comprehension involves understanding the specific information in the text, that is, the main ideas, facts and stated points of view. The literal level is a prerequisite for higher-level reading and thinking (Linde \& Fredrickson 2020). The inferential or interpretive level requires that readers or listeners make use of the information at the literal level to make inferences. At this level, readers can identify implicit relationships which are relationships that are not directly stated. Also at this level, readers can identify unstated reasons for actions or beliefs based on explicitly stated information or clues from the text. Conclusions can also be drawn based on specific facts, events, images, patterns or symbols found in the text (reading levels of comprehension [Mt. San Antonio College 2018]). At the critical or evaluative level, readers can understand ideas and information well enough to analyse, judge and critique the information and ideas. At this level, a reader is also able to explain and support their judgment clearly and can justify their stance (Mt. San Antonio College 2018). The critical or evaluative skill is required at the tertiary level where students will be exposed to more complicated materials. If students are poor in critical evaluation of texts or situations, they will not be able to cope with life challenges and academic studies. Apart from testing students' level of comprehension, other aspects like grammatical structure and functions, idiomatic expressions, figures of speech and vocabulary could also be tested in comprehension because examiners believe that mastery of all these aspects will aid comprehension. Nordquist (2019) opines that sentence structure in English grammar is arranging words, phrases and clauses in a sentence and that the grammatical function or meaning of a sentence hinges on this structural configuration. Organising expressions (thoughts) into structures suggests the intentions of the speaker or author to an audience. It is a technique that allows both the author and the audience to know what the author is trying to convey (Gitlina 2010). The understanding of the structures of the language is put into practice in compositions and comprehension passages where conscious consideration of the structure of the expression is used as a guideline to the meaning of the expression. Most students need some form of structure to their learning and to be actively and purposely engaged in their learning process. As a result, WAEC over the years (1988-2020) has tried to examine students' knowledge about grammatical structures and functions by asking them to identify some underlined expressions within the comprehension passages given to them in English Language examination. Over the years the questions have been similar in the sense that the same pattern of questions has been set, with slight variation in the number of questions. For example, the questions have been on literal, inferential, grammatical and idiomatic aspects.

Students' knowledge of vocabulary is very critical to the understanding of a text. Comprehension is better when the reader knows the meaning of most of the words. Hu and Nation (2000) reported that their participants needed to know $98 \%$ - 99\% of words in texts before adequate comprehension was possible, hence the importance of vocabulary cannot be overestimated. John (2017) opines that the link between vocabulary and the goal of reading comprehension is enormous. He further argues that if a student does not know the meaning of a word they will not be able to make sense of what they have read. Alqahtani (2015) posits that vocabulary knowledge is often viewed as a critical tool for second language learners because a limited vocabulary impedes successful communication. A robust vocabulary, however, advances all areas of communication in the second language which are listening, speaking, reading and writing (Alexander 2020). Students are asked to give the contextual meaning of words taken from a given comprehension passage in the WASSCE. For students to acquire more vocabulary, language researchers believe that students need to read extensively, to do so using different texts and to make reading a habit.

Understanding of figures of speech is also important. This is one of the aspects of comprehension that is tested in WASSCE. A figure of speech is a word or phrase using figurative language. It is language that has another meaning than its literal definition. A figure of speech relies on implied or suggested meaning, rather than a dictionary definition. The purpose of a figure of speech is to lend texture and colour to writing. An idiomatic expression (idiom) is an example of figurative expression (word or phrase) that has a meaning that is conventionally understood by native speakers. Idioms can be difficult to understand if a reader is not a native speaker of the language, because it is influenced by the culture and it allows a writer to draw on a rich cultural tradition and express complex ideas (Thyab 2016).

\section{Effect of schema on comprehension}

In presenting comprehension passages for examination, Garth-McCullough (2008) suggests that different perspectives such as the students' background knowledge (schemata), their socio-economic and cultural backgrounds should be taken into consideration. Rumelhart (1980) suggests that a schema theory is a theory about knowledge. Students' background or prior knowledge is an important factor in determining how readers process the information available in written texts (Garth-McCullough 2008). Comprehension requires the reader to link prior knowledge with the new knowledge for comprehension to take place. For readers to comprehend communicative material, they apply their beliefs about the world and what they already know about the present topic as a lens through which they interpret and understand the message the writer is trying to convey (GarthMcCullough 2008). The prior knowledge of students is in relation to some features of the text being read and these features include the origin of the text (local or foreign), source (newly composed text or an excerpt) and type (fiction, science, art, socio-economic, political, cross-cutting, historical, education). A text that is local in origin will likely contain ideas with which the students will be familiar. For example, a text addressing seasons of the year from the temperate environment would describe spring, summer, autumn and winter as against the rainy and dry seasons that the African 
students are familiar with. Students who have read widely stand the chance of having come across reading texts that are excerpts, hence finding the comprehension examination easy; this is in contrast to reading texts that are newly composed by the examiner. The type of text can limit the extent to which the readers' prior knowledge aids their understanding of the text. For instance, science-oriented texts treating issues such as climate change, the ozone layer and the greenhouse effect will most likely be strange to readers without a background in science. Widdowson (1978) observes that the learner may simply not feel himself in any way engaged by the text being presented to him' if they read texts not from their background. Ali (2016) confirmed in his research that linking the gist of the passages to 'real-world' language can provide a sense of purpose. These three attributes of the text to be read (source, origin and type) have effects on the extent to which the reader's prior knowledge helps them comprehend the text. Attributes of comprehension in this study are regarded as type, source and origin while the different aspects tested by examiners which have to do with the content of the comprehension are: literal, inferential, critical or evaluative, figures of speech, grammatical structures and their functions, idiomatic expression, and vocabulary.

\section{1st century literacy}

Literacy in the 21st century demands the ability to move confidently, efficiently and ethically between wide ranges of written and visual, print, live, digital or electronic text types according to purpose. (Primary English Teaching Association Australia [PETAA] n.d.)

'Reading competence has a significant impact on the future of students. It can affect their level of education after secondary school as well as their career choices and eventual lifestyles' (Hock \& Deshler, as cited in Joseph 2008). Students in secondary school should be prepared for bigger challenges that they will likely face in the higher institution and beyond by gradually introducing them to skills that will enable them to cope. It is therefore imperative that the literacy skills of students be developed in their entirety right from primary school through secondary school, and hence should be assessed in the WAEC examinations.

\section{Problems affecting comprehension}

Considering that reading is a foundational skill for all learning, students who experience problems in comprehending texts, may not be successful independent learners. They will have challenges that will have a significant impact on their academic success after secondary school (Bell 2004). The reason why comprehension challenges may impact negatively on students' success is that at the higher institution of learning there will be higher academic demands that will require higher cognitive tasks than what is being demanded in secondary school. Students who are adequately trained on how to use these skills from secondary school will have the potential of succeeding in their future endeavours. Oyinloye (2002) identifies some problems affecting students in comprehension examination such as the students' inability to identify the main ideas in a given passage, make inferences from what they have read, understand the information that is not directly stated, and identify the plot of the story. There are also some factors outside the classroom that affect language learning and achievement such as the socio-economic backgrounds of students. This can have an impact on language learning and achievement (Ginsborg 2014). Poor background in the English language may limit the ability of students to comprehend since English is not their first language. Students who grew up in homes where their parents are illiterate may not get academic assistance from home and there is usually a disconnection from school when they get home. Students who have educated parents are usually encouraged by their parents to read extensively.

Researchers in the past have tried to look into various areas of comprehension passages. Ali (2016) in his research investigated how background knowledge affects students' comprehension of passages using students from the Department of English, College of Arts, University of Basrah. It was discovered that students who received the background information before treatment comprehended the passage better. This suggests that passages where the students are familiar with the underlying concepts and themes are easier to comprehend. Thus, when examiners draw comprehension passages from sources in the students' local environment, they make it easier for the students to comprehend. Alonzo et al. (2009) in their research used a one-parameter Rasch model to examine the relative difficulty of different multiplechoice reading comprehension items assessing students' literal, inferential and evaluative comprehension of fictional narratives. The difficulty of questions derived from concepts identified as important components of reading comprehension by state content standards was also examined. These components include character, prediction and plot sequence. It was revealed from their findings that there is a curvilinear relationship between literal, inferential and evaluative comprehension. It was established that literal comprehension was the easiest while inferential and evaluative comprehension were considered to be more challenging. The findings also indicate that assessment objectives differ based on difficulty. This study examined the students' level of comprehension by asking multiple-choice questions. The main difference in this testing is that they did not test all of the other aspects such as figures of speech, grammatical structures and their functions, vocabulary and idiomatic expressions.

Researchers have used content analysis techniques to analyse the body of a text and other communication materials to identify concepts, themes and ideas that regularly occur within the texts and communication materials (Mayring 2014). The content analytical technique can be used to analyse education and examination materials (Kleinheksel et al. 2020). This study will use content analysis to locate the different aspects and levels of comprehension. 
This study intends to identify aspects of comprehension that are tested often in WASSCE to encourage teachers to lay more emphasis on those aspects when preparing students for the English Language examination. Students will also be enlightened on what they need to watch out for when reading any text to develop their cognitive strategies for reading comprehension, in particular for the WAEC examination.

\section{Theoretical framework}

This study spans two subject matter areas, namely reading comprehension and content analysis, which was used to analyse the comprehension examination given by WAEC at WASSCE. This study is tilted towards the cognitive interactive reading theories. Cognitive interactive reading theories place equal emphasis on a reader's schema and the print on the page as the basis of comprehending the content of the text (Cornejo 2014). These theories opine that instruction word, sentence and text meaning are accustomed, influenced or moulded by the whole set of experiences and knowledge the reader brings to reading (Kirby 2007). Reading is hence a dialogue between the reader and the text and it involves an active cognitive process in which the reader's background knowledge performs a crucial part in the construction of meaning (Shihab 2011). Thus, within the content analytical methodology employed in this study, the schema of the secondary school students was considered in terms of the attributes (type, source and origin) of the comprehension passages presented to the students by WAEC.

Content analysis is a method designed to identify and interpret meaning in recorded forms of communication by isolating the salient concepts and then creating a framework to organise the concepts in a way that can be used to describe a phenomenon (Kleinheksel et al. 2020). Mayring (2014) identified five modern hermeneutic approaches to content analysis; these are approaches in which the text has to be interpreted by the formulation of the analyst's preconceptions, the intentions of the text's author have to be found out and an additional explaining text has to be formulated. The five approaches are: (1) objective hermeneutics which draws inferences based on the objective of the social structures behind the text, (2) grounded theory which rests on a procedure of coding textual materials and defining the codes, (3) psychoanalytical text interpretation which was developed to draw inferences from the text to a deep structure of the contents, (4) phenomenological analysis which is directed at analysing the phenomenon through variation and reduction to its core concept, and (5) biographical analysis which interprets open-ended textual materials on individual life courses. This study utilises the grounded theory and phenomenological analysis approaches. Coding rules were developed based on some phenomena (attributes) unique to the comprehension passages and the questions.

The coding rules are the basis for categorisation and enumeration in content analytical techniques. The application of the categorisation process to the text identifies the relevant units that are unique to each category. Enumerations of the text based on the categorisation lead to the development of relative frequencies or other statistical indices of the distribution of categories. The statistical measures so computed are measures of permeation (Krippendorff 1967). For this study, the categorisation and enumeration resulted in the frequency counts that are presented in the tables.

Kleinheksel et al. (2020) classify content analysis into latent and manifest. Latent content analysis involves the interpretation of what is hidden deep within the text: the researcher attempts to discover the implied meaning in the text. Manifest analysis is conducted in a way that the researcher is thought to maintain distance and separation from the objects of study (texts). According to Krippendorff (1967), it is based on some message characteristic (categorisation) that produces uniformity of comprehension for a large majority of the audience, that is, it is intersubjectively verifiable. In this study, manifest content analysis was carried out. To ascertain the extent to which the categorisation will yield intersubjectively verifiable results, the inter-coder reliability test was also conducted.

\section{Methodology Research design}

The study was based on the analysis of secondary time series data. These data were secondary because they were not generated directly by the researcher and they were time series because they covered several years. The purposive sampling technique was used to select a time series of Paper I Section B of English Language questions of WASSCE covering 24 years. This section contains the comprehension passages. The questions for the 24 consecutive years were selected to ensure an adequate trend was available. In all, 48 passages were covered by the study. The main analytical approach used in this study was content analysis. The widely accepted term for systematic inquiries into communication is content analysis. To do content analysis, key symbols and themes items are classified and tabulated to ascertain their meanings and probable effects. Content analysis as a research method is a systematic and objective means of describing and quantifying phenomena (Downe-Wamboldt 1992; Sandelowski 1995). Content analysis is a research method used to make replicable and effective interpretations and coding textual material and it systematically evaluates texts such as documents, oral communication, and graphics (Gheyle \& Jacobs 2017). Duriau, Reger and Pfarrer (2007) define content analysis as a class of research methods at the intersection of the qualitative and quantitative traditions. It is promising for rigorous exploration of many important but difficult-to-study issues of interest. Comprehension is one such difficult issue because it is the ability to analyse, critique, evaluate and synthesise information from various sources. Many second language learners of English have challenges with comprehending texts not because they cannot read, but because reading requires making use of different types of 
skills at the same time. Comprehension could be influenced by the students' background, culture, socio-economic status, the teaching style of their teachers, among others. Franzosi (2004) describes content analysis as an objective, systematic and quantitative description of the content. For this study content analysis coding rules were used. The rules were developed specifically for analysing the selected comprehension passages. The rules were discussed with the other five WAEC examiners (these are English teachers who mark the WASSCE English Language Paper I) and reviewed based on their comments. An intercoder reliability test was conducted to test the reliability of the coding rules. To test for intercoder reliability, a reliability sub-sample was created. This comprised comprehension passage Paper I past questions for 3 years. Three research assistants were trained on how to use the coding rules. These comprehension passages were analysed based on the coding rules. The intercoder reliability is to ensure that the coding rules are appropriate and that the concepts coded are clear enough to enter into the spreadsheet. A concurrence of $80 \%$ and above implies that the coding rules and instructions are adequate to ensure intercoder reliability. If the concurrence is lower than $80 \%$, the coding rules will be revised and the coders retrained while the intercoder reliability test will be reconducted (Macnamara 2005). For this study, a concurrence of $82 \%$ was obtained.

The coding rules were used to analyse the content of the comprehension passages and corresponding questions were analysed for 24 years covered by the study. The output of the coding was initially entered into a spreadsheet before being exported to the statistical package for analysis. The analytical tools used were descriptive statistics comprising mainly frequency distribution, percentages, mean, median and mode. In carrying out content analysis, texts were analysed to determine the frequency of occurrence of specific concepts or words within the texts and coded into categories for building inferences. For the inferences to be valid, the classification procedure must be consistent (Weber 1990).

In Table 1, following Elo and Kynga (2008), the comprehension passages were categorised by type, source and origin. Types of comprehension were identified as fiction, science, art, socio-economic, political, cross-cutting, historical and educational while there were two sources: excerpt or newly composed. Origin consists of local, foreign or not known. These were the attributes of the comprehension passages. The aspects that dealt with the content of comprehension tested were: literal, inferential, critical or evaluative, figures of speech, idiomatic expression, grammatical structure and function, and vocabulary questions. These content subcategories were developed based on the literature reviewed and the WASSCE English Language curriculum. The contents of the comprehension passages and questions were then analysed and coded using the coding scheme.
TABLE 1: Coding scheme for content analysis.

\begin{tabular}{lll}
\hline Generic category & Sub-category & Items \\
\hline Passage attributes & Type & $\begin{array}{l}\text { Fiction, science, art, } \\
\text { socio-economic, political, } \\
\text { cross-cutting, historical, } \\
\text { education } \\
\text { Excerpt, newly composed } \\
\text { Local, foreign, not known }\end{array}$ \\
Question attributes & Oource & \\
& Literal meaning & \\
& Inferential meaning & \\
& Figures of speech \\
& Grammatical structures and \\
& $\begin{array}{l}\text { Meaning of idiomatic } \\
\text { expressions }\end{array}$ \\
& Critical or evaluative & \\
& Test of vocabulary & \\
\hline
\end{tabular}

Source: Adapted from Elo, S. \& Kynga, H., 2008, 'The qualitative content analysis process', Journal of Advanced Nursing 62(1), 107-115. https://doi.org/10.1111/j.1365-2648.2007.04569.x

\section{Results \\ Contents of comprehension passages tested in West African Senior Secondary School Certificate Examination}

\section{Type, source and origin of comprehension passages}

The attributes of the comprehension passages, namely type, source and origin of the passage, may influence the students' ability to comprehend the passages. Secondary school students are usually grouped into arts, commercial and science classes. While students in the arts and commercial classes may be disadvantaged if the comprehension passage is science-oriented, they may have an advantage if the passage falls into the category of socio-economic, historical and arts-related stories. Comprehension passages could be excerpts or newly composed. Excerpts are comprehension passages that were taken from a longer whole of any text. Passages that were newly composed are expected to be new to the students whereas it is not impossible that some of the students may have come across an excerpt; if that be the case, understanding such an excerpt will be easier for the reader. Comprehension passages that are local in origin will most likely address themes that are not completely strange to the students and this can aid comprehension.

\section{Types of comprehension passages}

The analysis of the comprehension passages based on the attribute type of comprehension passages is presented in Table 2. The table presents the frequency distribution of the types of comprehension passages for 24 years. The passages that are fiction had the highest percentage with $39.6 \%$. This was followed by passages dealing with socio-economic issues with $33.35 \%$ while science-related passages accounted for only $8.35 \%$ of the passages. Arts and political discourse passages had $4.2 \%$ each while historical and educational passages had $6.25 \%$ and $4.15 \%$. The fiction passages were the products of the examiners' imagination and there was no possibility of the candidates having come across the stories earlier. Also, the high preponderance of passages that are socio-economic may be a reflection of the importance of socio-economic challenges in national discourse in WAEC member countries. The examiners may assume the students 
TABLE 2: Types of comprehension passages.

\begin{tabular}{|c|c|c|c|c|c|c|c|}
\hline \multirow{2}{*}{$\begin{array}{l}\text { Type of } \\
\text { passage }\end{array}$} & \multicolumn{2}{|c|}{ Passage 1} & \multicolumn{2}{|c|}{ Passage 2} & \multicolumn{2}{|c|}{ Passages 1 and 2} & \multirow{2}{*}{$\begin{array}{c}\text { Mean } \\
\text { frequency } \\
\text { per year }\end{array}$} \\
\hline & Frequency & $\%$ & Frequency & $\%$ & Frequency & $\%$ & \\
\hline Fiction & 10 & 41.7 & 9 & 37.5 & 19 & 39.6 & 0.79 \\
\hline Science & 1 & 4.2 & 3 & 12.5 & 4 & 8.35 & 0.17 \\
\hline Arts & 1 & 4.2 & 1 & 4.2 & 2 & 4.2 & 0.08 \\
\hline $\begin{array}{l}\text { Socio- } \\
\text { economic }\end{array}$ & 6 & 25 & 10 & 41.7 & 16 & 33.35 & 0.67 \\
\hline Political & 1 & 4.2 & 1 & 4.2 & 2 & 4.2 & 0.08 \\
\hline Historical & 3 & 12.5 & 0 & 0 & 3 & 6.25 & 0.13 \\
\hline Education & 2 & 8.3 & 0 & 0 & 2 & 4.15 & 0.08 \\
\hline Total & 24 & 100.0 & 24 & 100.0 & 48 & 100.0 & - \\
\hline
\end{tabular}

need to be abreast of the critical socio-economic issues that were on the front burners of WAEC member countries. Issues covered in the passages include crime, cultism, marriage and unemployment. The implication of this is that teachers of English language comprehension need to cover the topical socio-economic issues in the countries while teaching the students. Also, they can encourage their students to read newspapers where they can obtain information on current issues and learn related vocabularies. The lower relative weights of arts and science-related passages mean that the examiners were conscious of the need not to put students who specialise in either of the two categories at a disadvantage in the English language comprehension examination. It could also be that the examiners expect students to at least have some knowledge in arts and science concepts in the course of their study in school. The science passages are in most cases educative and topical. Typical examples are discourse on ozone layer depletion and climate change.

\section{Sources of comprehension passages}

Table 3 presents the categorisation of comprehension passages by sources. There are just two sources: newly composed and excerpt. Newly composed passages were the passages that never existed before the examination, unlike excerpts which were drawn from already existing texts. The newly composed text has the highest frequency of occurrence with $87.5 \%$ while comprehensions that are excerpts have just $12.5 \%$ occurrence. The implication of this result is to inform teachers that they need to prepare the students by giving them different texts that will give the students different exposure to issues from all walks of life. This will help in developing their background knowledge which will eventually aid how they will comprehend the text as advised by Ali (2016) who confirmed in his research that linking the gist of the passages to 'real-world' language can provide a sense of purpose.

\section{Origins of comprehension passages}

Table 4 presents the categorisation of the comprehension passages based on origin. There are three categories under origin, namely local, foreign and not known. Comprehension passages that are local in origin have the highest frequency with $62.5 \%$ occurrence followed by passages whose sources are unknown with $29.15 \%$ of occurrence. Passages of foreign origin had the lowest frequency of occurrence at $8.35 \%$. Given this result, it appears the examiners are conscious of
TABLE 3: Sources of comprehension passages.

\begin{tabular}{lccccccccc}
\hline Sources & \multicolumn{2}{c}{ Passage $\mathbf{1}$} & & \multicolumn{2}{c}{ Passage $\mathbf{2}$} & & \multicolumn{2}{c}{ Passages 1 and 2 } \\
\cline { 2 - 3 } & Frequency & $\mathbf{\%}$ & & Frequency & $\mathbf{\%}$ & & Frequency & $\mathbf{\%}$ \\
\hline Excerpt & 3 & 12.5 & & 3 & 12.5 & & 6 & 12.5 \\
Newly composed & 21 & 87.5 & & 21 & 87.5 & & 42 & 87.5 \\
\hline Total & $\mathbf{2 4}$ & $\mathbf{1 0 0 . 0}$ & & $\mathbf{2 4}$ & $\mathbf{1 0 0 . 0}$ & & $\mathbf{4 8}$ & $\mathbf{1 0 0 . 0}$ \\
\hline
\end{tabular}

TABLE 4: Origin of the comprehension passages.

\begin{tabular}{|c|c|c|c|c|c|c|c|}
\hline \multirow[t]{2}{*}{ Origin } & \multicolumn{2}{|c|}{ Passage 1} & \multicolumn{2}{|c|}{ Passage 2} & \multicolumn{2}{|c|}{ Passages 1 and 2} & \multirow{2}{*}{$\begin{array}{c}\text { Mean } \\
\text { frequency } \\
\text { per year }\end{array}$} \\
\hline & Frequency & $\%$ & Frequency & $\%$ & Frequency & $\%$ & \\
\hline Local & 16 & 66.7 & 14 & 58.3 & 30 & 62.5 & 1.25 \\
\hline Foreign & 3 & 12.5 & 1 & 4.2 & 4 & 8.35 & 0.17 \\
\hline Not known & 5 & 20.8 & 9 & 37.5 & 14 & 29.15 & 0.58 \\
\hline Total & 24 & 100.0 & 24 & 100.0 & 48 & 100.0 & - \\
\hline
\end{tabular}

the fact that students will understand stories that they are familiar with, more than those that have a foreign background. Passages of local origin will be better understood because they will most likely contain ideas with which the students will be familiar. For example, a text addressing seasons of the year from the temperate environment would describe spring, summer, autumn and winter as against the rainy and dry seasons that the African students are familiar with. In literature, Garth-McCullough (2008) suggests that different perspectives such as the students' background knowledge (schemata), their socio-economic and cultural backgrounds should be taken into consideration.

\section{Relative importance of types of questions}

Table 5 shows that seven different types of questions were identified in the 48 passages covered. It also presents information on the frequency of occurrence of each type of question in the 48 passages. The types of questions presented to students in English language comprehension examination were literal, inferential, figures of speech, grammatical structure and functions, and idiomatic expression. The table also contains information on the average number of times (mean, median and mode) a particular type of question, for example literary questions, came up in a comprehension passage.

Table 5 shows that vocabulary questions and literal questions were the most frequent during the 24 years covered by the study. Each of them had a $97.9 \%$ frequency of occurrence. Further comparison of these two types of question reveals that literal meaning questions had an average rate of occurrence of four literary questions per passage while vocabulary test question had an average rate of occurrence of one question per passage. Teachers of English hence need to pay more attention to the two types of questions while teaching their students.

The next type of question that was important in terms of frequency of occurrence and hence should be given special attention by teachers of English language for the WASSCE is the grammatical structure which had the frequency occurrence of 93.75. The question with the lowest frequency of occurrence was critical or evaluative with $4.2 \%$. This is an 
TABLE 5: Relative importance of types of questions.

\begin{tabular}{|c|c|c|c|c|c|c|}
\hline \multirow[t]{2}{*}{ Type of question } & \multirow{2}{*}{$\begin{array}{l}\text { Frequency of } \\
\text { occurrence }\end{array}$} & \multirow[t]{2}{*}{$\%$} & \multicolumn{4}{|c|}{ Number of times questions occur in a yea } \\
\hline & & & Mean & Median & Mode & $\begin{array}{l}\text { Standard } \\
\text { deviation }\end{array}$ \\
\hline Literal meaning & 47 & 97.9 & 4 & 4 & 3 & 1.27 \\
\hline Inferential & 25 & 52.1 & 2 & 2 & 1 & 0.58 \\
\hline Figures of speech & 26 & 54.2 & 1 & 1 & 1 & 0 \\
\hline $\begin{array}{l}\text { Grammatical } \\
\text { structure }\end{array}$ & 45 & 93.8 & 1 & 1 & 1 & 0 \\
\hline $\begin{array}{l}\text { Idiomatic } \\
\text { expression }\end{array}$ & 10 & 20.9 & 1 & 1 & 1 & 0 \\
\hline $\begin{array}{l}\text { Critical or } \\
\text { evaluative }\end{array}$ & 2 & 4.2 & 1 & 1 & 1 & 0 \\
\hline Vocabulary & 47 & 97.9 & 1 & 1 & 1 & 0 \\
\hline
\end{tabular}

indication that in WASSCE students are not expected at this level to be saddled with higher-order thinking to a great extent.

\section{Discussion}

The research question addressed in this study is: what are the different contents of comprehension passages tested in WASSCE? The analysis of the passages was carried out focusing on 10 different content sub-categories (see Table 1). These are type, source and origin of comprehension passages; literal, inferential, figures of speech, grammatical structures and their functions, idiomatic expression, critical or evaluative, and test of vocabulary questions. The first three sub-categories were used to describe the attributes of the passages that may influence the students' ability to comprehend the passages while the remaining seven sub-categories are the aspects being tested in comprehension passages in WASSCE.

The results show that seven different types of comprehension passages could be identified: fiction, science, art, socioeconomic, political, historical and educational. The dominant ones were fiction which accounted for $39.6 \%$ of the passages, socio-economic $(33.35 \%)$ and science $(8.35 \%)$. Teachers of English language therefore ought to give their students opportunities to practise with the seven different types of passages while preparing for WASSCE. The relative importance of science-oriented passages shows that even an art student is expected to learn some science concepts in the course of their study. The science passages usually addressed educative and topical issues such as ozone layer depletion.

The sources of the comprehension passages show that $87.5 \%$ of the passages were 'newly composed'. The remaining passages were 'excerpts'. This implies that students should not expect passages they have come across before in the examination.

The results show that $62.5 \%$ of the passages had local origin while those of foreign origin were $8.35 \%$. The reason for this could be that the examiners are following the theory proposed by researchers that students comprehend better when they have the background knowledge that relates to the story (Garth-McCullough 2008; Ginsborg 2014). The students should hence be taught with passages addressing themes mostly from Nigeria or Africa.
The results of this study further show that the frequency of occurrence of literal questions is $97.9 \%$. This implies that English language examiners asked more literal questions. Literal understanding is the first and most basic level of comprehension in reading. Thus, mastering this component of reading development means being able to understand literally what the author said. Hence, teachers of English language should ensure that the development of literal comprehension reading starts from lower classes (primary schools) and develop this skill all through the students' secondary education. A student who can understand information that is explicitly stated in a text over time will improve and graduate to making inferences and critically evaluate text. It is a prerequisite for higher-level reading and thinking according to Linde and Fredickson (2020).

The frequency of occurrence of inferential questions was 52.1\%. This implies that inferential questions are significant on average. Hence, English language teachers need to teach students how to deduce meanings that are not directly stated in the passage. Teachers should draw students' attention to questions like this each time comprehension passages are given in class. This will help them to know the difference between inferential and literal questions. The teacher can also ensure that students are properly drilled. They can give students assignments on reading text that is a little taxing but interesting just to build the students' skill in grammar, vocabulary, idiomatic expressions, among others. Teachers can also encourage their students to read widely because that will expose them to cultures that they may not be familiar with but might have heard about in books.

The frequency of occurrence of figures of speech was $54.2 \%$. This implies that there was a $54.2 \%$ chance that figures of speech questions will occur in the examination. The English language teachers, therefore, need to teach their students the different types of figures of speech in English so that students can easily identify them at any time they come across them in a comprehension passage or use them appropriately even in their own communication when writing or speaking. Reading extensively should be encouraged among students to build their knowledge in English language culture, vocabularies, figurative and idiomatic expressions.

Grammatical structure and function questions had a frequency occurrence of $93.75 \%$, thus implying that they are inevitable in WASSCE. Therefore, teachers should ensure that students are taught properly in class how to address them in comprehension passages. This is a question that has been consistently asked in WASSCE over the years.

The idiomatic expression questions had a frequency occurrence of $20.85 \%$. This result implies that idiomatic expression questions are seldom asked. This should guide teachers in the allocation of their time to this aspect of English language comprehension. The examiners of WASSCE were not expecting the students to have much mastery of idiomatic expressions. The reason for this may be that it was considered to be difficult to understand for students that are not native 
speakers of the English language since it is influenced by the culture and it allows a writer to draw on a rich cultural tradition that is not common to second language learners. Teachers must lay emphasis on this aspect because these students need to have all-round development that will enhance not only comprehension but help them improve academically.

With a frequency occurrence of $97.9 \%$, vocabulary test questions were very important, hence students and teachers of English language should devote adequate time to vocabulary while covering the curriculum. Furthermore, vocabulary questions attract 1 mark for each word tested and could attract up to 10 or 12 marks out of the 40 marks allocated to comprehension passages in WASSCE. The teacher can encourage healthy competition on reading with a prize to compensate whoever reads up to two or three books in a week. The school library should be properly equipped with recent and relevant books.

Critical or evaluative questions had a frequency of occurrence of just $4.2 \%$. This shows that these questions are rarely asked. This may be because WASSCE examiners may believe critical or evaluative questions are above the standards required from the students. Irrespective of this, critical evaluation skill is required by the students, especially in tertiary institutions. It has been confirmed by many researchers that students who are not good at comprehension of texts cannot do well academically (Jude \& Ajayi 2012; Rutzler 2020). At the tertiary level of education, students move into advanced learning. Students who do not have a good foundation in comprehension may not gain admission into such institutions. If by chance they find themselves there, they may not be able to cope. At this level, students will be exposed to more complicated materials. Hence, the teachers should devote adequate time to teaching this aspect even if WASSCE does not emphasise it. The examiners, curriculum planners, Ministry of Education and all stakeholders should take into cognisance the importance of critical or evaluative comprehension skill and ensure students are adequately trained on how to answer such questions in the examination.

\section{Conclusion}

This study is a content analysis of aspects and levels of reading comprehension passages tested in WASSCE. The study was based on the analysis of secondary time series data of WASSCE Paper I Section B of English Language questions covering 24 years. The questions were selected to ensure an adequate trend was available. In all, 48 passages were covered by the study. This study identified the key aspects of WASSCE English language comprehension questions being tested by classifying them by question attributes which are: literal, grammatical structure, vocabulary, inferential and figures of speech. Others are idiomatic expression and critical or evaluative questions (Table 1). The result revealed that more emphasis was laid on literal questions while WASSCE seems not to lay emphasis on critical or evaluative questions and this is considered to be of concern because this skill is highly required by students in higher institutions and people in all walks of life. The other category is the passage attributes which are: type, source and origin (Table 1). It was revealed that most of the types of comprehension passages being presented in WASSCE were newly composed and they related to the students' local environment. This is quite encouraging because it will help the students to some extent to relate with the passages and this will help in providing background information that can help in comprehension. The main objective of this study was directed at analysing the content of the English language comprehension questions in the WASSCE to identify the intensities of testing different aspects of comprehension to raise teachers' awareness on the different levels of comprehension. This will have implications on teaching and will help the students become better comprehenders and readers. This will encourage teachers to lay emphasis on these aspects when they teach reading strategies to their students. This objective was met and it revealed that literal questions occurred frequently and that critical or evaluative questions were rarely asked. This was eye-opening and a solution for change in the area that concerns critical or evaluative questions that were rarely asked was proffered to examiners, teachers, curriculum planners and all stakeholders.

\section{Recommendations}

In line with the findings and conclusion of this study, the following recommendations are made: each aspect of the comprehension passages identified by the study should be covered by English language teachers when preparing their students for English language examination and the teachers should allocate more time to teaching the aspects with high relative importance over time. Teachers should employ methods of teaching that will cater for inferential questions in comprehension passages. The critical or evaluative skill questions that are rarely asked in WASSCE should be given more attention by teachers whether it is tested or not because it is a requirement for the current demands of literacy in the 21st century. Students who are just leaving secondary school will require the critical or evaluative skill because it is essential in attaining higher education and having the skill can earn an individual a decent job, which in return will improve their living standard and contribution to society at large.

In the light of the pedagogic importance of critical or evaluative questions, it is recommended that examiners and teachers should lay emphasis on questions that demand higher-order reasoning to prepare students for the contemporary demands of literacy. The curriculum and the WASSCE should be amended to encourage critical or evaluative thinking among secondary school students since it is an important part of all literacy and language.

\section{Acknowledgements}

I sincerely appreciate my supervisor Prof. G.O. Oyinloye, Ekiti State University, Ado-Ekiti, who encouraged me to embark on this research, Prof. Titi Fola-Adebayo, Federal University of Technology, Akure, who is my mentor in academics and J.U. Anyaele, who compiled the senior secondary school certificate past questions and answers for 
SSCE, GCE and NECO English language theory/objectives with oral English, 1988-2017.

\section{Competing interests}

The author hereby declares that no competing interests exist.

\section{Author's contributions}

F.M.O. is the sole author of this research article.

\section{Ethical considerations}

This article followed all ethical standards for research without direct contact with human or animal subjects.

\section{Funding information}

This research received no specific grant from any funding agency in the public, commercial or not-for-profit sectors.

\section{Data availability}

The author confirms that the data supporting the findings of this study are available within the article.

\section{Disclaimer}

The views and opinions expressed in this article are those of the author and do not necessarily reflect the official policy or position of any affiliated agency of the author.

\section{References}

Alexander, F., 2020, Understanding vocabulary, viewed 28 May 2020, from https:// www.scholastic.com/teachers/articles/teaching-content/understandingvocabulary/

Ali, Q., 2016, 'The impact of schema theory on reading comprehension', Journal of Basrah Researches: Humanities 41(2), 12-20. https://doi.org/10.33762/0694041-002-016

Alonzo, J., Basaraba, D., Tindal, G. \& Carriveau, R., 2009, 'They read, but how well do they understand? An empirical look at the nuances of measuring reading comprehension', Assessment for Effective Intervention 35(1), 34-44. https://doi. org/10.1177/1534508408330082

Alqahtani, M.A., 2015, 'Teaching English for specific purposes: Attitude among Saudi engineering students', English Language Teaching 8(7), 76

Bell, S., 2004, 'Transforming seniors who don't read into graduates who do', English Journal 95(5), 36-41. https://doi.org/10.2307/4128933

Cabral, A.P. \& Tavares, J., 2002, 'Reading and writing skills in higher education Lecturers' opinions and perceptions', paper presented at the European Conference on Educational Research, University of Lisbon, 11-14 September, pp. 11-14.

Centre for Canadian Language Benchmarks, 2015, Edition, 294 Albert Street, Suite 400 Ottawa, ON K1P 6E6, viewed 11 April 2020 from https://iclba.language.ca/wpcontent/uploads/2017/05/4.-Developing-Receptive-Skills-Assessment-Tasks.pdf

Compton College, n.d., Levels of comprehension, viewed 11 April 2021, from https:// vibdoc.com/queue/levels-of-comprehension-compton-college-5f0c220aca966.html

Cornejo, G., 2014, Reading Theories and Their Relationship to Reading Instruction viewed 28 June 2020, from https://www.slideshare.net/angelicamaecornejo1/ reading-theories-pp.

Downe-Wamboldt, B., 1992, 'Content analysis: Method, applications and issues', Health Care for Women International 13(3), 313-321. https://doi. org/10.1080/07399339209516006

Duriau, V., Reger, R. \& Pfarrer, M., 2007, 'A content analysis of the content analysis literature in organization studies: Research themes, data sources, and
methodological refinements', Organization Research Methods 10(1), 5-34. methodological refinements', Organization
https://doi.org/10.1177/1094428106289252

Elo, S. \& Kynga, H., 2008, 'The qualitative content analysis process', Journal of Advanced Nursing 62(1), 107-115.https://doi.org/10.1111/j.1365-2648.2007.04569.x

Fairbairn, G. \& Winch, C., 1996, Reading, writing and reasoning, Open University Press, Buckingham.

Franzosi, R., 2004, 'Content analysis', in A. Bryman \& M. Hardy (eds.), Handbook of data analysis, pp. 547-566, Sage, Beverly Hills, CA.
Garth-McCullough, R., 2008, 'Untapped cultural support: The influence of culturally bound prior knowledge on comprehension performance', Reading Horizons: A Journal of Literacy and Language Arts 49(1), 1-30.

Gheyle, N. \& Jacobs, T., 2017, Content Analysis: A short overview. Internal research note. Retrieved 20 May 2020 from http://hdl.handle.net/1854/LU-8543687

Ginsborg, J., 2014, The effects of socio-economic status on..., viewed 13 June 2018 , from https://www.researchgate.net/publication/237448474 The Effects of Socio-Economic_Status_on_Children's_Language_Acquisition_and_Use

Gitlina, G., 2010, 'The cognition of grammatical structures', Procedia Social and Behavioral Sciences 2(2), 4147-4151. https://doi.org/10.1016/j.sbspro.2010.03.655

Grisso, L.C., 2018, 'The relationship between English language proficiency and academic achievement in English language learners', Doctoral dissertation, Liberty University, Lynchburg, VA.

Hu, M. \& Nation, P., 2000, Unknown vocabulary density and reading comprehension. Reading in a foreign language, 13.

John, K., 2017, The importance of vocabulary for reading comprehension, viewed 28 May 2020, from https://johnkennyweb.wordpress.com/2017/09/19/theimportance-of-vocabulary-for-reading-comprehension/

Joseph, N., 2008, 'Preparing secondary students for 21st century literacy through content-area reading instruction', Language Arts Journal of Michigan 23(2), Article 10. https://doi.org/10.9707/2168-149X.1124

Jude, W.I. \& Ajayi, O.B., 2012, 'Literal level of student's comprehension in Nigeria: A means for growing a new generation African scholars', Journal of Education and Practice 3(7), 120-129.

Kirby, J., 2007, Reading comprehension: Its nature and development, Canadian Language and Literacy Research Network, viewed 22 February 2020, from http:// www.literacyencyclopedia.ca/pdfs/topic.php?topld=227

Kleinheksel, A.J., Winston, N.R., Tawfik, H. \& Wyatt, T.R., 2020, 'Qualitative research in pharmacy education: Demystifying content analysis', American Journal of Pharmaceutical Education 84(1), 7113. https://doi.org/10.5688/ajpe7113

Krippendorff, K., 1967, 'An examination of content analysis: A proposal for a general framework and an information calculus for message analytic situations', Doctoral dissertation, University of Illinois, viewed 15 April 2020 from http://repository. upenn.edu/asc_papers/250

Lasisi, M.J., 2003, The components of reading. Teaching reading in Nigeria: $A$ guidebook to theory and practice, International Reading Association, Newark, DE.

Linde, S. \& Fredrickson, A., 2020, Essential reading comprehension skills, viewed 05 December 2019 from https://study.com/academy/lesson/essential-readingcomprehension-skills.html

Mayring, P., 2014, Qualitative content analysis: Theoretical foundation, basic procedures and software solution, Klagenfurt, viewed 15 April 2020 from https:// nbn-resolving.org/urn:nbn:de:0168-ssoar-395173

Moore, A., 2016, The importance of comprehension skills in learning, viewed 20 May 2020 from https://blog.agradeahead.com/post/importance-comprehensio-skillslearning/\#

Mt. San Antonio College, 2018, Levels of Comprehension, viewed 22 April 2020, from https://mtsac.instructure.com/courses/56468/pages/levels-of-comprehension? module_item_id $=492152$

Nordquist, R., 2019, English language sentence structure, viewed 28 May 2020, from https://www.thoughtco.com/sentence-structure-english-grammar-1691891

Ofodu, G., Babalola, J. \& Dada, E., 2010, Aspects of language and communication skills, Vintage Publishers, Ibadan, p. 92.

Oyetunde, T.O., 2002, 'How do secondary school students process prints?', in A. Lawa, I. Isiugo-Abanihe \& I.N. Ohia (eds.), Perspectives on applied linguistics in language and literature, p. 11, Stirling-Horden Publishers, Ibadan.

Oyinloye, G.O., 2002, Basic elements of comprehension, summary and writing skills, for schools colleges, Bifocal Publishers, Lagos.

Primary English Teaching Association Australia (PETAA), n.d., Position papers Approaches to early reading instruction, viewed 23 June 2020, from https://www. petaa.edu.au/w/About/PETAA Position_Papers/w/About/PETAA_position papers.aspx?hkey=20cba852-0cd4-45e0-bae7-ec24e3f87115

Reading Theories and Their Relationship to Reading Instruction, 2014, viewed 28 June 2020, from https://www.slideshare.net/angelicamaecornejo1/reading-theories-pp

Rumelhart, D., 1980, 'Schemata: The building blocks of cognition', in R. Spiro, B. Bruce \& W. Brewer (eds.), Theoretical issues in reading comprehension, pp. 33-58,
Erlbaum Associates, Mahway, viewed 13 April 2021 from https://www.mathgenie. Erlbaum Associates, Mahway, viewed 13 April 2021
com/blog/importance-of-reading-comprehension

Sandelowski, M., 1995, 'Qualitative analysis: What it is and how to begin?', Research in Nursing \& Health 18(4), 371-375. https://doi.org/10.1002/nur.4770180411

Shihab, I.A., 2011, 'Reading as critical thinking', Asian Social Science 7(8), viewed 10 January 2020 from www.ccsenet.org/ass.

Stoffelsma, L. \& Spooren, W., 2019, 'The relationship between English reading proficiency and academic achievement of first-year science and mathematics students in a multilingual context', International Journal of Science and Mathematics Education 17, 905-922. https://doi.org/10.1007/s10763-018-9905-z

Thyab, R.A., 2016, 'The necessity of idiomatic expressions to English language learners', International Journal of English and Literature 7(7), 106-111. https:// doi.org/10.5897/IJEL2016.0895

Weber, R.P., 1990, 'Basic content analysis, second ed.', Quantitative Applications in the Social Sciences 49, Sage Publications Ltd., London.

Widdowson, H.G., 1978, Teaching language as a communication, Oxford University Press, Oxford 